\title{
Experimentation using delta winglet type vortex generator attached on tube surface of tube in tube heat exchanger for heat transfer augmentation
}

\author{
Sandip B. Kharge*, N.C.Ghuge, V.S. Daund \\ Mechanical department, University of pune, Matoshri college of Engineering and Research Centre, Eklahare, Nashik, Maharashtra, India \\ Accepted 15 June 2016, Available online 20 June 2016, Special Issue-5 (June 2016)
}

\begin{abstract}
The Vortex generator is responsible for creating the turbulence in flow of fluid. In this work experiment is carried out to enhance the heat transfer coefficient with installing delta winglet type of vortex generator in tube in tube type heat exchanger. These vortex generators are directly welded on internal side of tubes of tube in tube heat exchanger. These vortex generator causes stream wise longitudinal vortices in the tube which disrupt the growth of thermal boundary layer and enhance the heat transfer rate. Influence of geometrical parameter such as aspect ratio, winglet attack angle on heat transfer will be studied on rectangular, square, triangular and delta type winglet vortex generator and also pressure drop is calculated to find out the effect of it on heat transfer rate. Air is taken as working fluid, the flow regime is assumed to be laminar. By varying the above parameter the heat transfer coefficient will be calculated and by comparing all result optimum Dimension of winglet will be achieved.
\end{abstract}

Keywords: Winglet attack angle, vortex generator, delta winglet, rectangular winglet, square winglet, triangular winglet.

\section{Introduction}

The heat exchanger is complex device that provides the transfer of thermal energy between two or more fluids, which are at different temperature and are in thermal contact with each other. Tube in tube heat exchanger consists of two tubes, inner and outer coiled together. This unique, compact design prevents thermal fatigue, increases efficiency and reduces overall size. It is ideal for high temperature, high pressure and low flow application. This type of heat exchanger are used for cooling, heating or reheating of fluids, gases or air in wide range of industries, such as chemicals processing, hydro carbon processing etc. Heat transfer enhancement in tube in tube heat exchanger is possible by providing the vortex generator tube. Vortex generator is device which produces turbulence in the flow. These vortex generators are in the form of wings or winglets. These vortex generators are of triangular, rectangular or delta shapes which can weld or punched and bend out of plates so that they project into flow with angle of attack to main flow direction. When trailing edge is attached to tube is called as wing and when the chord length is attached to tube is called as winglet. In this delta winglet type vortex generator is used which are mounted directly inner surface of tube

*Corresponding author: Sandip B. Kharge either by welding, embossing. By varying size of winglet and by varying their configuration heat transfer coefficient will be calculated. Every day large amounts of heat are transferred in many industrial and domestic processes. As a result, any performance increase of the heat transfer will have a significant impact on energy use, fuel consumption and the resulting greenhouse gas emissions.

A wavy rectangular winglet type vortex generator was studied by (A.A. Gholami, et al 2014). For heat transfer enhancement. Heat transfer enhancement and pressure loss penalty for fin-and-tube compact heat exchangers with the wavy-up and wavy-down rectangular winglets as special forms of winglet are numerically investigated in a relatively low Reynolds number flow. The effect of Reynolds numbers from 400 to 800 and angle of attack of $30^{\circ}$ of wavy rectangular winglets are also examined.

(Khoshvaght-Aliabad et al1994) studied rectangular wings in plate fin heat exchanger and changes the various geometrical parameters. A type of plate-fin channel with rectangular wings as a transverse vortex-generator channel was considered. In this of the project, the influences of seven effective geometrical parameters(i.e. wings height, wings width, channel length, longitudinal wings pitch, transverse wings pitch, wings attach angle, and wings attack angle) for three conventional coolants flow (i.e. water, 
oil, and ethylene glycol) at the laminar flow regime were evaluated. As the third part of the project, general correlations were derived for Nusselt number of the coolants flow inside the plate-fin heat exchangers with vortex-generator channels.

A plain channel is representative of single element of plain-fin cross flow heat exchangers. (Tiggelbeck et al.2002) investigated heat transfer enhancement and flow loss in a channel with double rows of punched delta-winglet pairs. The flow structures behind the second row were observed to be qualitatively similar where the vortices exhibited more unsteadiness in both configurations. At $\mathrm{Re}=4600$ and an attack angle of $45^{\circ}$, the aligned geometry yielded $60 \%$ increase in heat transfer

(Biswas et al 1998) et al. computed laminar flow and heat transfer characteristics associated with a punched delta wing or winglet pair in a rectangular channel. Inclusion of the holes beneath in the computational domain was found to reduce the average Nusselt number and the friction coefficient. Their simulation also indicated that the delta wing performed better than the winglet pair in heat transfer but was less effective in terms of entropy generation based on an irreversibility analysis.

(Gentry et al 2002) measured vortex strength, local and average mass transfer, and pressure drop in a developing channel flow with a delta wing placed at the leading edge. It was revealed that tip vortices had a significant impact on transport characteristics for both walls. Local enhancements as high as $150 \%$ were found in regions where a vortex induced a normal inflow.

(Yuan et al 2003). investigated heat transfer and pressure drop in a duct mounted with rectangularwinglet rows. Their work confirmed superiority of longitudinal vortices to transverse vortices in heat transfer augmentation. Over the parametric space considered, the impact of duct aspect ratio on thermalhydraulic performance was found to be much more significant than the winglet spacing.

(Dietz et al.2006) employed the commercial software FLUENT to compute heat transfer and velocity field in a turbulent channel flow for Reynolds numbers between 80,000-600,000. The effects of number of delta wings lateral and longitudinal displacement were analyzed. For a number of two wings, variation in the

Longitudinal displacement had little influence on the enhancement. Addition of a third wing did not improve heat transfer appreciably.

(Wu and Tao 2012) performed a numerical study on heat transfer and flow characteristics in a rectangular channel with punched VGs at various geometries. Under affixed VG area, a delta-winglet pair introduced higher heat transfer than a rectangular winglet pair and judiciously decreasing the aspect ratio of rectangular VGs (defined as height to chord length) could yield further enhancement at a modest pressure drop penalty. Min et al. compared performance between two winglet shapes, rectangle and octagon (by cutting off the four corners of a rectangle). Their experimental results favored the octagon winglet as it induced higher heat transfer and lower friction for the same VG area.

(Fiebig et al 2002) measured 55-65\% heat transfer augmentation with $20-45 \%$ increase in the apparent friction factor in the Reynolds number range 600-2700 for an inline arrangement of three tube rows. For the staggered tube pattern, the associated increases became much lower (below 9\%). The improvement was found more pronounced for low-to-moderate Reynolds numbers $(<2000)$.

(O'Brien et al 2005) measured local and overall heat transfer coefficients in a fully developed channel fitted with a circular cylinder and/or a delta-winglet pair over a Reynolds number range based on channel height of 670-6300. For elements with three tube rows, the delta-winglet pairs at $30^{\circ}$ enhanced the average Nusselt number by $16-20 \%$ and simultaneously decreased pressure drop by $8-10 \%$ over a Reynolds number range of 800-2000.

\section{Objective}

In this present experiment the following objectives have been set to find out effect on heat transfer augmentation by using various winglet shapes on the surface of tube in tube heat exchanger

1) To find out heat transfer coefficient using delta winglet type vortex generator in tube in tube heat exchanger.

2) To investigate the effect of winglet shape i.e. Delta, triangular, rectangular and square.

The existing literature include heat augmentation by varying effective geometrical parameters (i.e. wings height, wings width, channel length, longitudinal wings pitch, transverse wings pitch, wings attach angle) in heat exchanger of inserts. Also heat augmentation is done by changing shapes of inserts like rectangular, triangular, trapezoidal etc. But this process is very complicated to make the inserts of various shapes also these types of inserts gives poor heat transfer rate than delta winglet vortex generators. Hence if we use delta winglet type vortex generators on surface of heat exchanger than using various types of inserts will give better heat transfer rate and low pressure drop. After discussion on literature survey, this work was taken in to consideration for improving heat transfer augmentation in tube in tube heat exchanger using delta winglet type vortex generators by changing geometrical change in to it. Thus use of delta winglet on surface of heat exchanger is to be done. The problem statement for project is to understand passive technique- delta winglet shape with geometrical modification like varying shapes and its effect on heat transfer augmentation for tube in tube heat exchanger

\section{Experimentation}

The experimental setup consists of following main components 


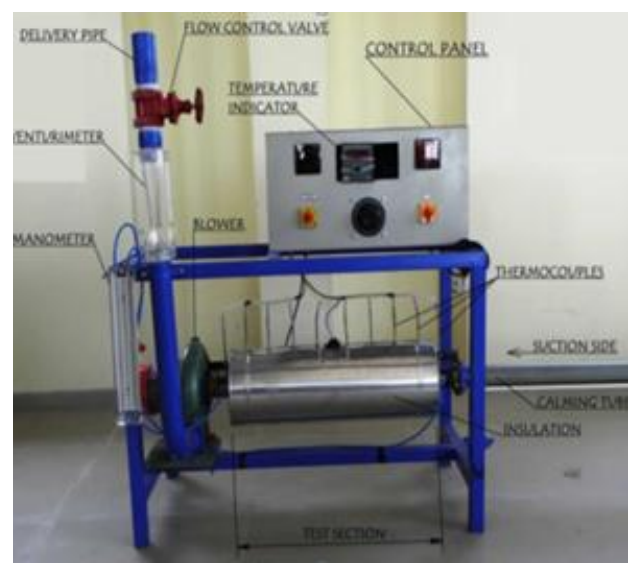

Fig.1 Experimental setup

\section{Calming Tube:}

The Calming tube section is provided to allow the flow to be hydro-dynamically fully developed.

2. Venturi meter:

It is used to measure the mass flow rate, and thereby velocity of water. The venturi meter is fitted across the delivery side of the pump to avoid the effect of its back pressure on test section. The volumetric flow rates from the pump were adjusted by flow control valve fitted at delivery end.

\section{Manometer:}

U-tube manometer is used to measure the pressure drop across the test section. The range of the manometer is $0-300 \mathrm{~mm}$ of water column.

4. Heater:

Uniform heat flux is applied to the test tube by heating it with band heater. The mechanism of heat production is based on principle of electrical resistance heating. The electrical output power can be controlled by a dimmer stat to provide constant heat flux along the entire length of the test section. The capacity of heater is 300 watt, $230 \mathrm{~V} \mathrm{AC}$ supply is to be provided.

5. Thermocouples and Control Panel:

The surface temperature of the tube wall is measured by $\mathrm{K}$ type thermocouples, which are placed on the surface of the tube. Eight thermocouples are placed on the surface of the test section to measure the surface temperature and two thermocouples are placed at the inlet and outlet of the test section to measure the inlet and outlet temperature of the water. To measure the outer surface temperature of insulation two thermocouples are mounted at outer surface of insulation. The range of thermocouple is 0$200^{\circ}$ C.Control Panel consist of dimmer stat, temperature indicator and on-off switch.

\subsection{Selection of vortex generator}

I. Vortex generators are proposed in different geometries such as Delta rectangular, winglet, triangular etc.

II. Winglet and triangular vortex generators are the simplest types which the least pressure drop is reported for them referred from literature survey.
III. The best size dimensions for length to height ratio are 2 to 1 for winglets to have the best heat transfer referred from literature survey.

IV.The best angle of attach is reported $30^{\circ}$. By increasing the angle of attack, both pressure drop and heat transfer will be increased referred from literature survey.

\subsubsection{Delta winglet shape}
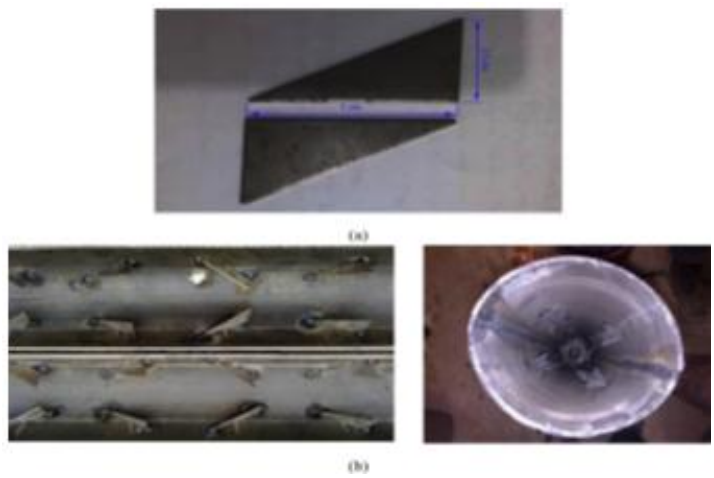

Fig. 2 a) Delta winglet shape, b) inside view of heat exchanger

As shown in fig winglet height is $2.5 \mathrm{~cm}$ winglet base length is $5 \mathrm{~cm}$. These delta winglet shapes are attached to inside of surface with attach angle $30^{\circ}$.

\subsubsection{Triangular shape}

As discussed in selection of vortex generator best size dimensions for length to height ratio are 2 to 1 for winglets to have the best heat transfer. And hence winglet Base length is selected as $5 \mathrm{~cm}$ and winglet height is selected as $2.5 \mathrm{~cm}$.These type of vortex generator are also are attached to inside of surface with attach angle $30^{\circ}$.

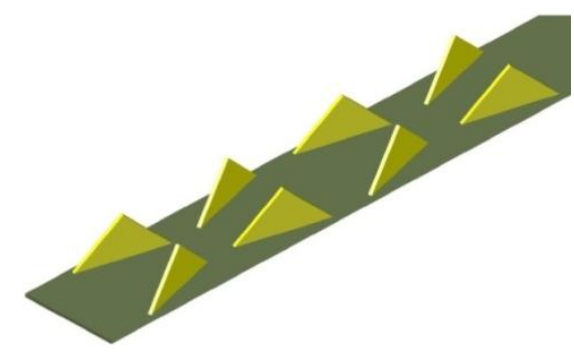

Fig.3 Triangular winglet shape

\subsubsection{Rectangular shape}

Same for rectangular type of vortex generator best size dimensions for length to height ratio are 2 to 1 for winglets to have the best heat transfer and hence winglet Base length is selected as $5 \mathrm{~cm}$ and winglet height is selected as $2.5 \mathrm{~cm}$.These type of vortex generator are also are attached to inside of surface with attach angle 30 ․ 


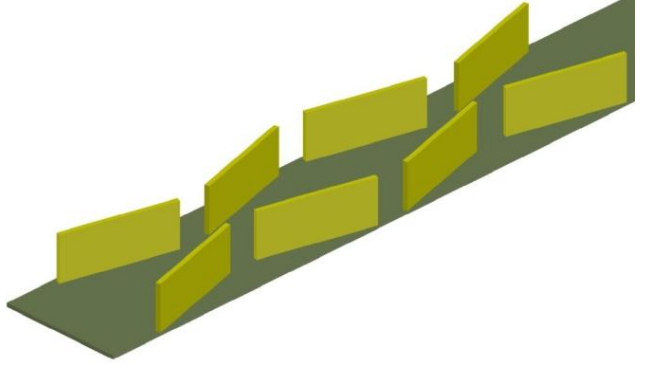

Fig. 4 Rectangular winglet shape

\subsubsection{Square shape}

For square type of vortex generator best size dimensions for length to height ratio are 1 to 1 for winglets to have the best heat transfer and hence winglet Base length is selected as $5 \mathrm{~cm}$ and winglet height is selected as $5 \mathrm{~cm}$.These type of vortex generator are also are attached to inside of surface with attach angle $30^{\circ}$.

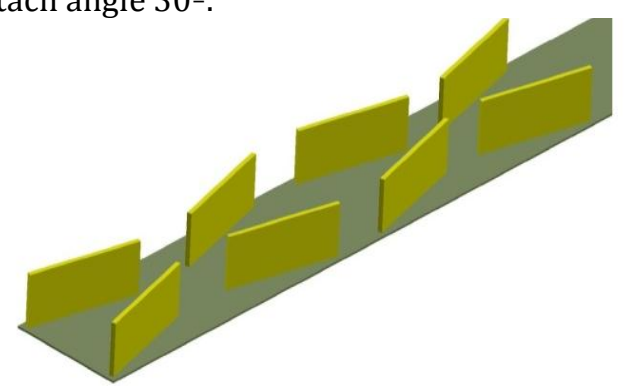

Fig. 5 Square winglet shape

3) Specification

Dimensions of test section

- Length of Test Section: $600 \mathrm{~mm}$.

- Length of Calming Section: $1000 \mathrm{~mm}$.

- Inner Diameter of Tube (Di): $54 \mathrm{~mm}$.

Table 1. Design parameter

\begin{tabular}{|c|c|c|c|}
\hline $\begin{array}{c}\text { Delta } \\
\text { winglet }\end{array}$ & $\begin{array}{c}\text { Rectangular } \\
\text { winglet }\end{array}$ & $\begin{array}{c}\text { Square } \\
\text { winglet }\end{array}$ & $\begin{array}{c}\text { Triangular } \\
\text { winglet }\end{array}$ \\
\hline \multicolumn{4}{|c|}{ Base length $\times$ Height } \\
\hline $\begin{array}{l}5 \mathrm{~cm} \times \\
2.5 \mathrm{~cm}\end{array}$ & $5 \mathrm{~cm} \times 2.5 \mathrm{~cm}$ & $5 \mathrm{~cm} \times 5 \mathrm{~cm}$ & $5 \mathrm{~cm} \times 2.5 \mathrm{~cm}$ \\
\hline $4 \mathrm{~cm} \times 2 \mathrm{~cm}$ & -- & -- & -- \\
\hline $\begin{array}{l}3 \mathrm{~cm} \times \\
1.5 \mathrm{~cm}\end{array}$ & -- & -- & -- \\
\hline
\end{tabular}

As from previous study delta winglet shape can give better heat transfer rate and hence only size of delta winglet is changed.

\section{Result \& discussion}

\subsection{Validation}

To check the accuracy and correctness of the given experimentation here the comparison made between the smooth tube result and result obtained from the previous correlations. To validate the experimental setup correlations used are Gnielinski correlation for Nusselt number and Petukhov Correlation For friction factor.

Gnielinski correlation for Nusselt number is given as,

$$
N u=\frac{(f \div 8)(\operatorname{Re}-1000) \operatorname{Pr}}{1+12.7(f \div 8)^{0.5}\left(\operatorname{Pr}^{2 / 3}-1\right)}
$$

Petukhov Correlation For friction factor is given as,

$$
f=(0.790 \ln \operatorname{Re}-1.64)^{-2}
$$

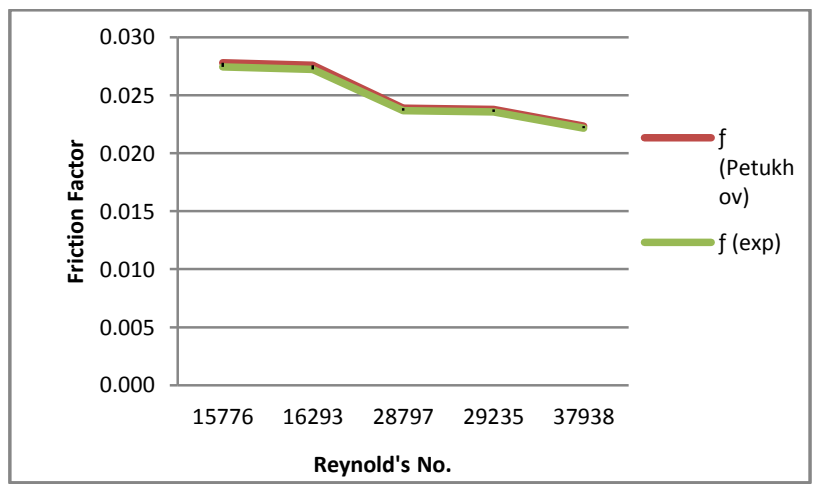

Fig. 6 Friction Factor- Reynolds No. for smooth tube

Friction factor calculated from the correlation for friction factor and friction factor calculated by experimentally are near about same that means our experimental setup is giving accurate readings.

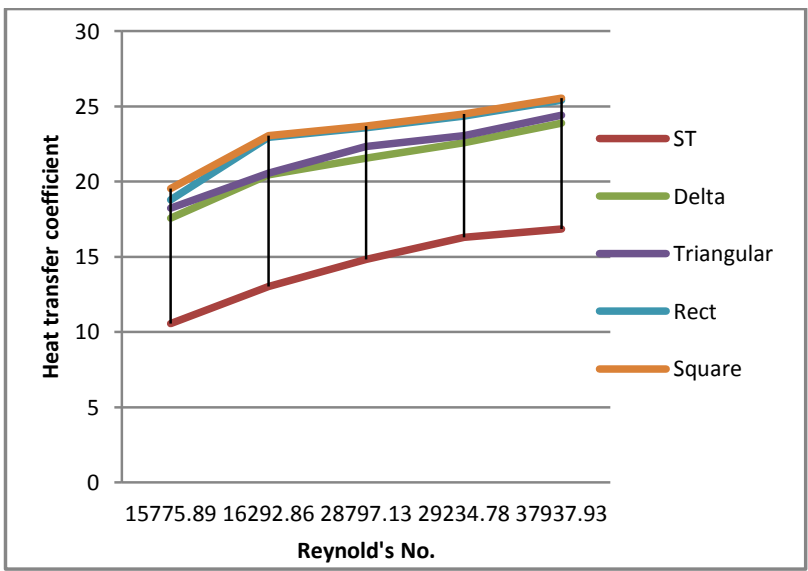

Fig. 7 Heat transfer coefficient -Reynolds No. for various Configurations

Heat transfer coefficient for all configuration such as Delta rectangular triangular and square found by experimentally and plotted against the Reynolds number. It is found that Delta type vortex generator has more heat transfer coefficient than other type of vortex generator. By inserting delta winglet type of 
vortex generator heat transfer coefficient increased by $32.5 \%$ as compared with smooth tube.

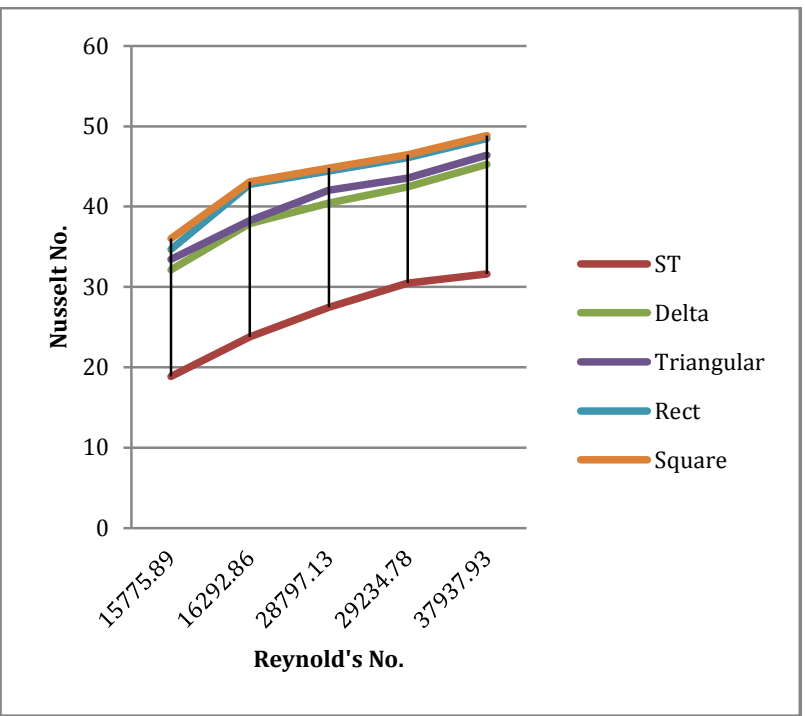

Fig.8 Nusselt No. - Reynolds No. for various configurations

Nusselt Number for all configuration such as Delta rectangular triangular and square found by experimentally and plotted against the Reynolds number. It is found that among all configuration Delta type vortex generator has largest value of Nusselt Number than other type of vortex generator i.e. 36.015.

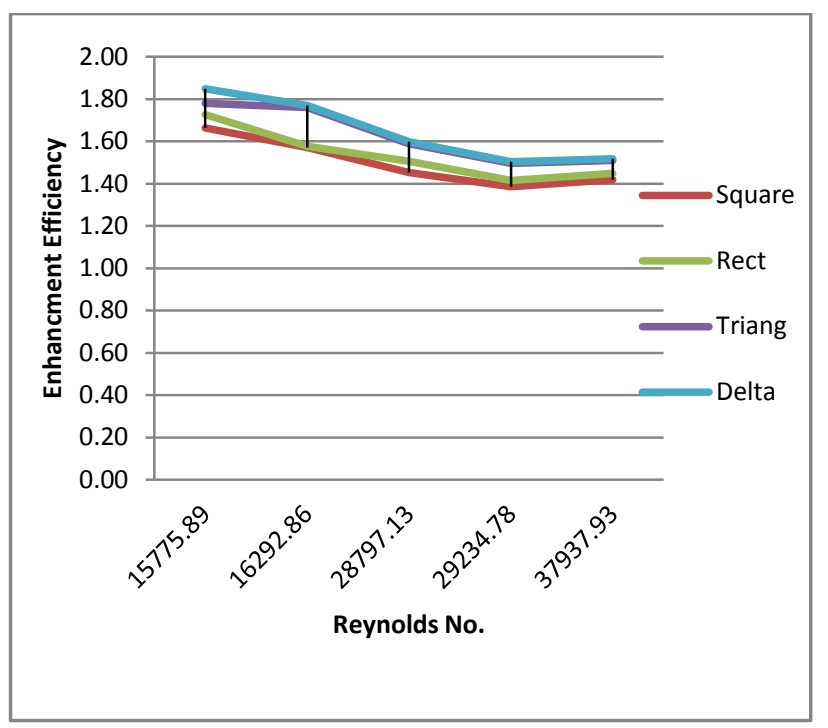

Fig 9 Enhancement Efficiency- Reynolds No. for various configurations

Amongst the configuration tested for Delta type vortex generator gives the best enhancement efficiency of 1.85 at Reynolds number 15775.89.

Experimentation is done by researchers on different aspect ratio $(1,1.33,2)$ and different attack $\left(20^{\circ}, 30^{\circ}, 40^{\circ}\right)$ angle and result is compared as follows:.

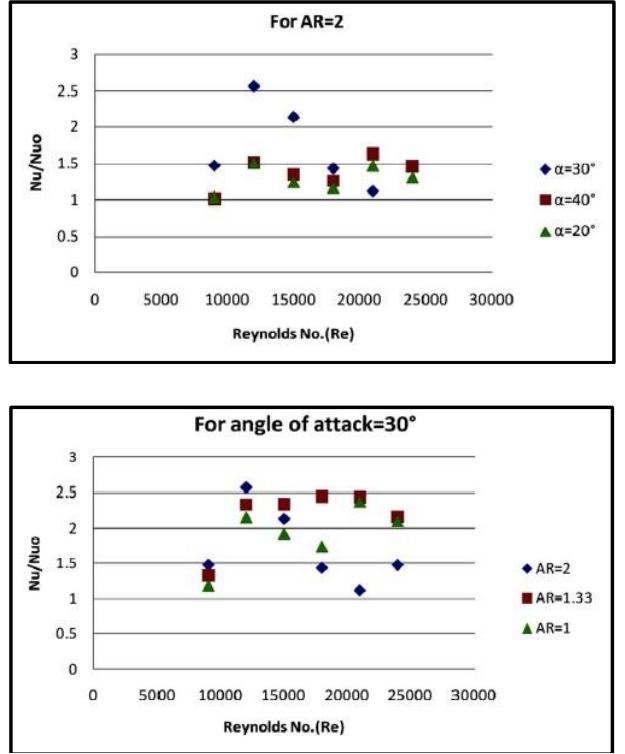

Fig. 10 Heat transfer coefficient -Reynolds No. for various aspect ratio and for various attack angle attack angle

From graph researcher concluded that heat transfer coefficient is high at aspect ratio 2 and at $30^{\circ}$ attack angle at low Reynolds number and hence high heat transfer rate.

\section{Conclusions}

As from various graphs plotted for various configuration it is concluded that Heat transfer Coefficient is higher in delta Winglet Vortex generator and hence Heat transfer rate in Delta type winglet vortex generator is more than other types of vortex generator as compared with triangular winglet shape, rectangular winglet shape and square winglet shape. Also Enhancement efficiency is greater in delta type winglet vortex generator is more than other type of vortex generator. Also among the entire configuration from delta winglet type of vortex generator configuration having aspect ratio $3 \mathrm{~cm} \times 1.5 \mathrm{~cm}$ has highest heat transfer coefficient.

\section{References}

A.A. Gholami, MazlanA.Wahid, Heat transfer enhancement and pressure drop for fin-andtube compact heat exchangers with wavy rectangular winglet-type vortex generators International Communications in Heat and Mass Transfer (2014)

G. Biswas,N.K.Mitra,M. Fiebig,Heat transfer enhancement in fin-tube heat exchangers by winglet type vortex generators, Int. J. Heat Mass Transf. 37 (2) (1994) 283-291.

Tiggelbeck.,K. Torii, K.M. Kwak, K. Nishino, Heat transfer enhancement accompanyin pressure-loss reduction with winglet-type vortex generators for fin-tube heat pressure-loss reduction with winglet-type vortex gent
exchangers, Int. J. Heat Mass Transfer 45 (2002) 3795-3801.

Gentry, M. C., 1998, Heat Transfer Enhancement Using Tip and Junction Vortices, Ph.D. dissertation, University of Illinois, Urbana, IL.Gentry and jaction Vortices, Ph.D. dissertation, University of Illinois, Urbana, IL.Gentry and jacobi, Perform
comparison of some tube inserts, Int. Comm. Heat Mass Transfer, 29, 45-56 (2002).

Yuan, Z.-X., Tao, and Yan, X. T., 2003, Experimental Study on Heat Transfer in Ducts with

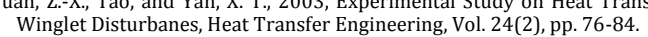

Dietz, C. F., Henze, M., Neumann, S. O., Wolfersdorf, J. von, and Weigand, B., 2006, The Effects of Vortex Structures on Heat Transfer and Flow Field BehindMultielement Arrays of of Vortex Structures on Heat Transfer and Flow Field BehindMultielement Arrays of Vortex Generators,
Paper No. HTE-12.

Wu, J. M., Zhang, H., Yan, C. H., and Wang, Y., 2012, Experimental Study on the Performance of a Novel Fin-Tube Air Heat Exchanger with Punched Longitudinal Vortex Generator Energy Conversion and Management, Vol. 57, pp. 42-48.

Min C Qi, C . Kong X and Dong J. 2010, Experimental Study of Rectangular Channel with Modified Rectan X., and Dong, J., 2010, Expen pr. 42 -48. Modified Rectangular Longitudinal Vortex Generators, International journal of Heat and
Mass Transfer, Vol. 53, pp. 3023-3029.

and Design, Vol. 76(2), pp. 108-123. 'Brien

Exchangers with Winglets, ASME Journal of Heat Transfer, Vol. 127, pp. 171-178. 